\title{
Can knowledge be created exclusively from online sources? A business intelligence approach in ecommerce
}

\author{
Grigoraș Mihnea GÎNGIOVEANU LUPULESCU \\ Bucharest University of Economic Studies, Bucharest, Romania \\ mihnea.gingioveanu@gmail.com \\ Francisca Elena ZAMFIR \\ Bucharest University of Economic Studies, Bucharest, Romania \\ zamfir.francisca@yahoo.com
}

\begin{abstract}
As more and more business data is generated and made available in the online environment, it makes sense for all the business components to start and take advantage of this trend. One of the components that we targeted in this paper is business knowledge, more precisely gathering enough data and information in order to generate knowledge about a business, also known as business intelligence. But this could not be done without taking into account the global pandemic that started in 2020 and continued to this day, accelerating the business digitization trend exponentially. Numerous papers related to the forced digitization of businesses due to Covid-19 have been published in 2020, most of them being focused on job loss, business model shifts, the economic impact and governmental stimulus effect in various industries. The current paper is focused on the business knowledge creation, more exactly on how and where to find data and information in an exclusively online manner about Romanian ecommerce companies, that can then be processed in order to obtain business knowledge. We researched three Romanian ecommerce websites in order to see if meaningful knowledge about their business approach can be extracted, all being done entirely from online sources, with no physical connection or relation to the targeted companies. In order to achieve this, we used public traffic data from websites like www.trafic.ro, financial data from www.listafirme.ro and also tested a few other key metrics of the websites. We managed to identify a very interesting situation concerning the three ecommerce websites while also outlining a simple workflow that can be duplicated by anyone in order to obtain basic business intelligence about Romanian internet-focused companies.
\end{abstract}

Keywords: Knowledge Creation, Online Sources, Ecommerce, Business Intelligence, Digitization, E-Business.

\section{Introduction}

As we all know, 2020 was a year of massive shifts in the business environment, mostly due to the global pandemic that still continues to this day. The free movement restrictions and the physical distancing rules translated into a massive digitalization trend all over the world, with almost all businesses moving at least some part of their activity online and some going even full digital (Paunescu \& Matyus, 2020).

Nevertheless, interactions between the companies did not cease to exist, on the contrary, the surge of new players in the online environment generated even more competition between them and the already existing online companies. So, naturally, the need for business knowledge in the online environment also grew, motivating us to write this paper (Bratianu et al. 2020). We took things even one step further by trying to find all the data and information for this research in an exclusively online manner, thus creating a simple workflow that can be replicated by anyone for free with just an internet connection. The workflow that we are going to present further should 
allow for anyone to extract meaningful knowledge about Romanian ecommerce websites, from anywhere, anytime.

The data for doing this study was gathered from online data aggregators like www.trafic.ro and www.listafirme.ro. Also, browsers like Google Chrome were used to test certain properties of the researched websites, as well as social media platforms like Facebook, Instagram and YouTube. After we processed all the data and information about the three websites, we managed to corroborate everything into a very interesting discovery, one that was not clear at the first sigh, assimilating it as business knowledge. Although the data used for this study is in no way statistically significant enough to offer us the big picture over time, we consider that it is sufficient to showcase how one company managed to adapt to the "pandemic period of 2020", reinforcing its position on the market. The three websites that we researched were ecommerce websites that operated in the car tire niche. More detailed information and also the workflow used for this paper can be found bellow.

\section{Literature review}

In business as in most fields, knowledge represents one of the most important resources that a company may own, having a significant contribution to both its organizational performance and competitive advantage (Bratianu et al., 2020). Each and every organization has its own understanding and definition of knowledge, one that is often influenced by the company knowledge sources and information flow structure. Not all information and knowledge models are suited for all companies, each company having its own needs and requirements, especially in the long run (Gavurova et al., 2020). While some organizations are focused on technology when it comes to creating and managing knowledge, some are still 'old-fashioned', having people at the center of all their decisions (Dinca, 2020).

The current trend, taking into consideration the global pandemic that affected a lot of business domains in 2020 and still goes to this day, is to combine technology as much as possible with people. Thus, more and more employees are now teleworkers, working and doing most of their activities from home. Although this concept was initially viewed with skepticism, most people believing that in the long term (more than 6 months) this kind of work could affect the abilities and social skills of people, studies actually showed that the amount of autonomy teleworkers received was actually beneficial. People working from home started to develop an intrinsic desire to develop themselves, both personally and professionally, proving that telework can be a sustainable work system in the long run (Dima et al., 2019).

Nowadays, a lot of information can be found on internet platforms and social media. Technology has transformed the local and the international business environment almost irreversibly, even the smallest of the SME's having an online presence. Yet, the extent of this massive shift and what it means for the business domain is not fully understood. Multiple findings and papers published in the recent years indicate that internet sources and platforms can generate (via human interaction, of course) both tacit and explicit forms of knowledge, thus opening a massive new world full of potential (Glavas, 2019).

\section{Methodology}

As stated above, the current paper aims to find ways in which knowledge can be created exclusively in an online manner, adapting and trying to be in accordance with the times we live in. The starting point for this research was the data obtained using www.trafic.ro, this being the leader in web 
auditing, rankings and real-time statistics for Romanian websites. The number of views for each of the three websites between December 2019 and November 2020 was extracted and summarized in an Excel table, which was then used to obtain the chart presented in the section bellow.

Likewise, the revenue for each of the companies that owned the websites was extracted from www.listafirme.ro, one of the best online platforms that offer public data regarding Romanian companies. This time, the data series started with 2017 and ended in 2019, as 2017 was the year that the 'youngest' of the examined companies was created, so older data could not be used in a comparison between the companies.

Last but not least, we developed seven elements which we concluded to be important when it comes to websites, tested the three websites for each of the elements and then ranked them between 1 and 5, with 1 meaning that the website could use some improvement for that particular element and 5 meaning that the website has a great implementation of that specific element. The seven elements were: mobile responsiveness (how well the website works on mobile devices), appearance (how intuitive and easy the website is to navigate), loading time (how fast can the website be accessed), social media presence (we looked for the number of likes/followers on Facebook, Instagram and YouTube), public reviews (we looked for the number and the ranking each website had, especially the Google reviews, as those appear first when looking for a website), prices (we compared the prices of seven identical products, shared by all the websites in their offer) and product range (we compared five similar product categories in order to determine which of the websites had a larger product offer). Just as mentioned before, the data was centralized in a table in Excel and used to create the charts presented in the results section bellow. Although this data set is far from being statistically significant in the long term, we strongly believe that the data is sufficient for gathering information and knowledge in order to determine what the year 2020 looked like for the companies in question. At the same time, we encourage anyone that has interest in our study to enhance the data set as time goes by and see if our conclusions are still valid in the future.

As far as qualitative research methods go, we tried to have a holistic approach for this case study. Ecommerce businesses cannot be reduced to simple websites were people can buy products or services, as that would not explain why the internet has hundreds of thousands of this kind of websites, but just a handful are actually profitable in each niche. Frequently, an ecommerce business is more than the sum of its components, having numerous system dynamics and complex interdependencies that can be observed and understood using complex tools like OLAP (Ferreira et al., 2017). Although for this case study we did not had enough data to use online analytical processing (OLAP) as our main method of research, we still had in mind a multidimensional and context sensitive approach while processing the results of the research.

\section{Results and discussions}

The three websites that were analyzed in this paper are: www.anvelope-astral.ro, www.e-pneus.ro and www.anvelope-torom.ro. For the ease of reading and comprehension of the paper, we renamed them Website A, Website B and respectively Website C. All three websites are actually ecommerce businesses that activate in the car tire domain/niche, having a similar online presence and business approach (or so we thought when we initially choose them for this study). The main scope we had in mind was to see how each of the three developed in the recent year (also having in mind the global pandemic situation) while also trying to extract useful knowledge about the three businesses using exclusively online sources. In order to get the initial data and have a good starting point for the study, we downloaded and then summarized the number of views that each website had in the 
last 12 months from www.trafic.ro. The number of views for each of the three websites can be consulted in Figure 1 bellow.

As we can observe in the graph, for the first half of 2020, Website A has more than double the number of views that Website B has, which should relate, in the ecommerce business, to more revenue for the Website A. However, starting with April 2020, Website B most likely started to

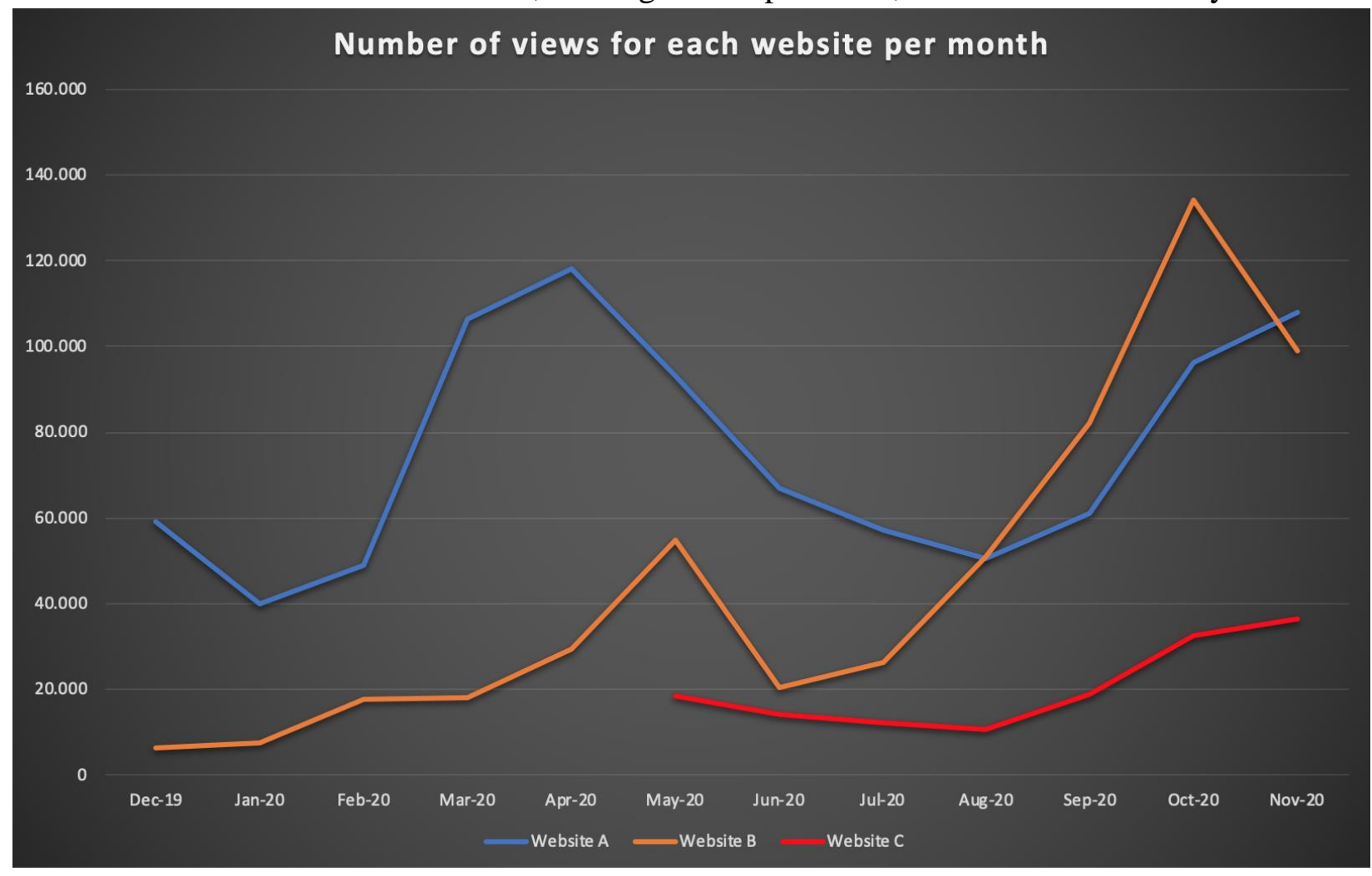

PICBE |

122

Figure SEQ Figure $l^{*}$ ARABIC 1 - Number of website views in the last 12 moths for the three analyzed websites

Source: www.trafic.ro/vizitatori/top-siteuri-auto-moto.

invest in marketing and website optimization, getting closer as far as the number of views go, to Website A. This could have been a direct result of the fact that in the spring people switch to summer tires, thus increasing revenues in the tire business for all the players. Correlating this information with the fact that in April the global Covid-19 pandemic was still on a upward trend, it is safe to assume that Website B saw this as an opportunity to invest in their website and catch up with Website A.

What is really interesting is that we have data for Website C starting only with May 2020, suggesting that this is the time when the website was created (this information will be relevant in the second part of the paper). During the second half of 2020, Website $C$ has much lower view numbers that the other two website, but in general, starting with August 2020, has an upward trend.

So, if we were to draw an early conclusion at this point using just this data, we could assume that out of the three, Website A is the mature player on the car tire market, Website B is a serious competitor that aims to surpass Website $\mathrm{A}$ and Website $\mathrm{C}$ is the new player that has potential but is still far from the first two.

With this initial information in mind, we decided to examine the three websites even closely. In order to do that, we elaborated seven criteria/elements that we found to be important for 
an ecommerce business and ranked each of the three websites depending on the results we had from testing them. The results can be seen in the Figure 2 bellow. We focused our criteria's mainly on the user experience (UX) but also on the regular business metrics, like product range and prices (Stefani, 2018). The first element that we checked was the property of the website to be mobile

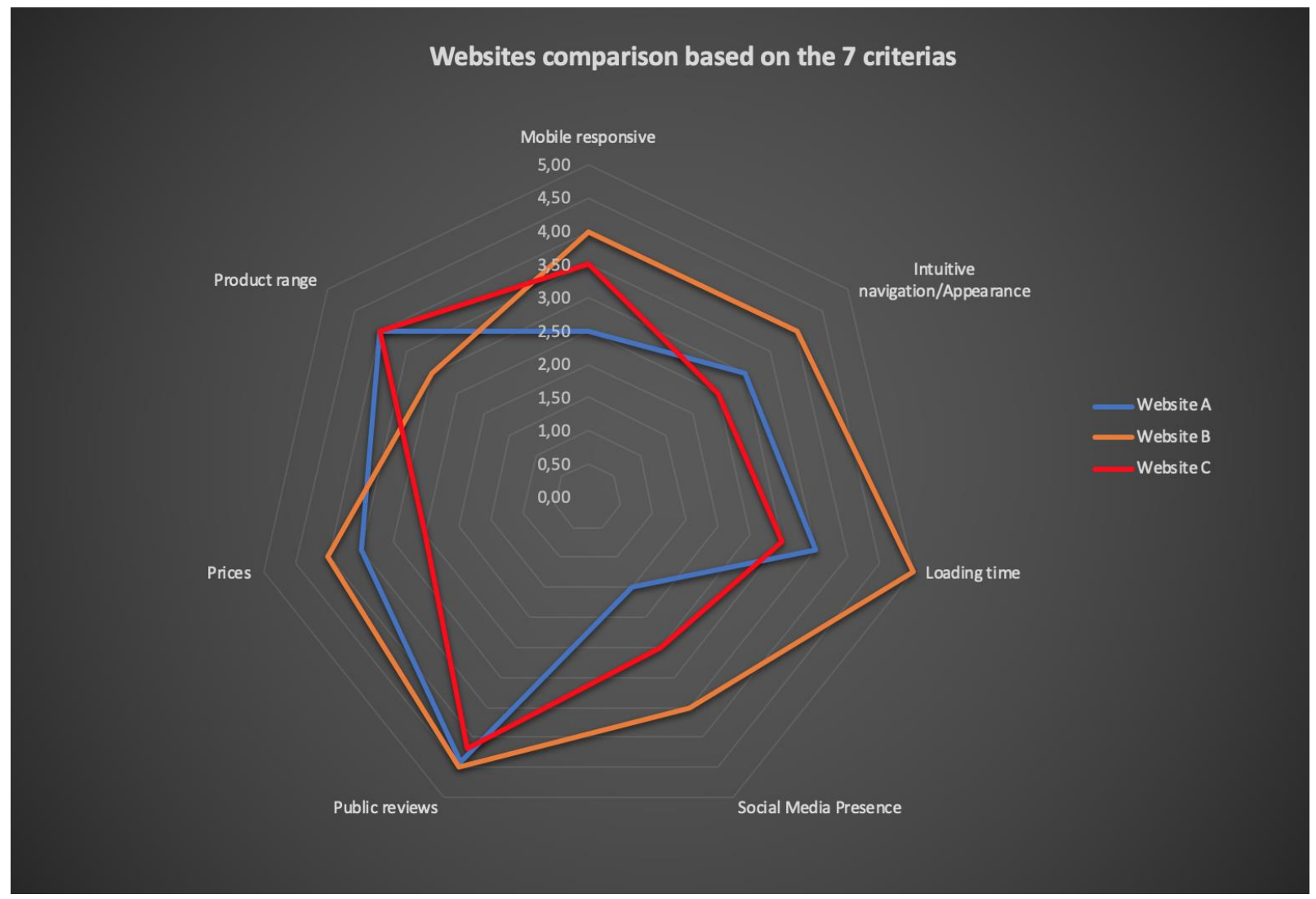

Figure SEQ Figure ${ }^{*}$ ARABIC 2 - Elaborated criteria comparison between the three websites

Source: Authors' own research results.

responsive. In order to do that, we used a mobile device (iPhone 11 Pro) and the DevTools option available in Google Chrome browser. We then opened each website both on the mobile device and different tablet screen emulations (using Google Chrome DevTools). Out of the three websites, Website B was the most "responsive" and adapted best to all screen ratios. It was closely followed by Website C, with almost similar results. Website A was the least "responsive" out of the three websites, with product images not being entirely visible and some elements being displaced.

Next, we checked how intuitive the website interface is, how difficult it is to search for a tire size and how easy it is to find a certain menu or product. Again, Website B had the most intuitive and good-looking interface, with Website $\mathrm{A}$ and Website $\mathrm{C}$ being close, with lower rankings. The third criteria that we checked was the loading time of the website. This was pretty straight forward to check, using a timer and a computer connected to the same internet network for all the three tests. The clear winner was Website B, having much faster load times that Website A and Website C.

The fourth examined criterion was the social media presence. In order to examine this, we checked for the websites presence on Facebook, Instagram, YouTube and even verified if they offer WhatsApp support for their clients (or similar services). This time the three websites were 
evenly "distanced", with Website B having the most likes on Facebook and WhatsApp support integrated in the website, followed by Website $\mathrm{C}$ with a Facebook page integration and ending with Website A having no integration and the lowest number of likes on their Facebook page.

Next in line, we looked at the number of public reviews that can be found for each of the websites and also at the "grade" or number of stars averaged by each website from the reviews. This was the closest criteria between the three websites, all of them having mostly positive feedback (in average) and a close number of stars (4.4 for Website A, 4.4 for Website B and 4.1 for Website C). The majority of the reviews were found on Google Reviews and www.compari.ro, with Website A having more than 770 public reviews.

The sixth evaluated criteria was the price at which the websites commercialize their products. In order to quantify this and rank the website accordingly, we choose six products that could be found on all three websites and compared their prices. Website B had the best prices out of the three, followed closely by Website A. Website $\mathrm{C}$ had the biggest average prices for the six products that we compared, in average it's prices being with $6.4 \%$ larger than Website B.

Finally, we checked for the product rage offered by each website. In order to find this out, we compared five product categories (tire sizes) and also checked for the number of brands that the websites offer. Website A and Website $\mathrm{C}$ had a very similar offer (which will soon make sense), with Website B having a lower product offer, but still covering a decent range of tire sizes.

After we put everything together in the graph presented in Figure 2, we started to observe a pattern occurring. Website $\mathrm{A}$ and Website $\mathrm{C}$ had somewhat similar characteristics, while Website $\mathrm{B}$ differentiated itself, having a focus on the user experience and the social media presence. This intrigued us to search even deeper and look for more information about the three websites, and what we found is very interesting, in our opinion. By identifying the companies behind the three ecommerce websites, we found that Website A and Website C are actually owned by the same company named S.C. Torom International S.R.L., while Website B is owned by S.C. Pneus Expert Online S.R.L. The first company, Torom International, was founded back in 1997, also having a physical location that offers tire change services for its customers. Pneus Expert Online is an exclusive ecommerce business founded in 2016, being the newcomer out of the two. This can also be observe by looking at the revenues of the two companies in the Figure 3 bellow.

Like all mature companies, Torom International has a steady income that is most likely based on loyal customers that return each year, being satisfied with the company products and services. On the other hand, although Pneus Expert Online is a young company, we can observe that in only three years it almost doubled its revenues, having a healthy growth rate. This was done by offering slightly better prices and a much better overall user interface. So, it is safe to assume that this is a classic case of an old and experienced company versus a new and optimized company, that aims to obtain some of the market share from the more experienced one.

Also, by having all this new information, we can now make sense on why we have data for Website C only starting with May 2020. It is clear that in order to retain as much of the market share as possible, Torom International seized the opportunity and fragmented its customer base by creating a new website (Website C). As we can see in Figure 2, this new site was more focused on the social media presence together with being better adapted to mobile devices. As a differentiator, Torom International increased the prices for the products offered throughout Website $\mathrm{C}$, trying to emulate a more premium ecommerce seller in order to differentiate itself from competition. This technique is also known as advertising up or premium pricing strategy (Ivan et al., 2018). The main idea behind this pricing strategy is to create the illusion or the perception for the customer that the offered products/services have a higher value than similar products or services offered be the 


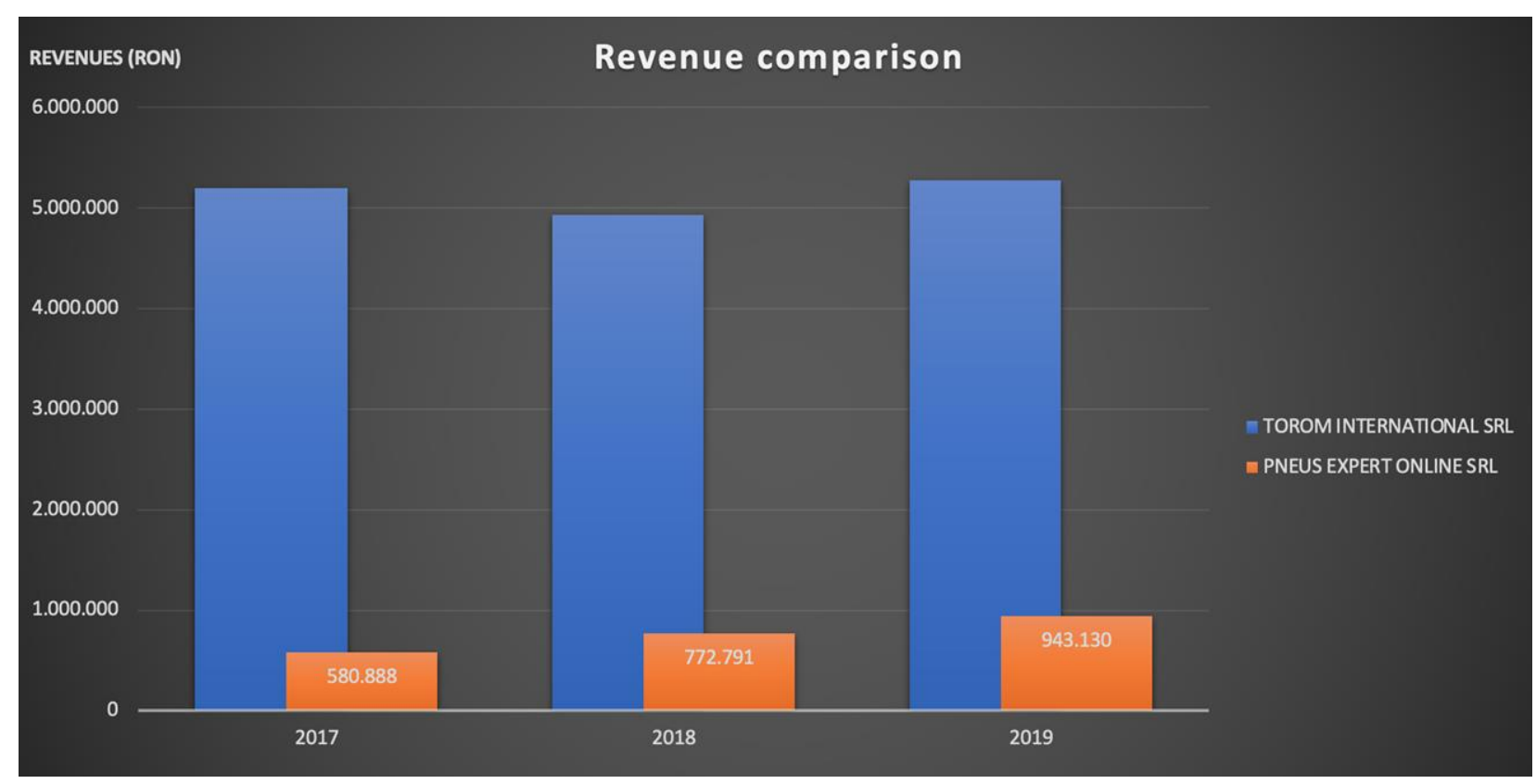

PICBE |

125

Figure SEQ Figure ${ }^{*}$ ARABIC 3 - Revenue comparison between the two companies for the last three years

Source: www.listafirme.ro.

competitors, just because the prices of the company are higher (Mahdavi et al., 2019). While applying this strategy, the company is betting mostly of the fact that the customers will not search the internet for more similar products and compare them, but rather look at the reviews and trust that the products/services are indeed high quality. The marketing department aims in this case to try and convince the consumers that the name of the website (as it is an ecommerce business) is enough to ensure the trust that a customer needs to place an order (Woodruff, 2020).

By corroborating all this information, we can see how Torom International managed to keep itself in a good position on the car tire market by creating a second website and applying a different pricing strategy. This maintained the company total number of views for the two websites above its main competitor (Pneus Expert Online) and reinforced the strong position on the market that the organization already had.

\section{Conclusion}

As shown in the research above, nowadays a lot of data and information can be found in online sources, lowering the entry barrier (from an informational and financial point of view) for basic business intelligence type of analyzes. What initially looked like three ordinary ecommerce websites, with no apparent connection, turned out to actually be a very interesting situation in which a company defended and reinforced its position on the market.

In this paper, we presented a simple workflow that can be used for gathering data about Romanian websites, with no cost or initial information being required. The first step in doing so, is to get data about the website traffic. One of the best ways to do that is to use www.listafirme.ro, a platform specialized in website monitoring that also offers a limited number of insights for free (for detailed data, a paid account is required). Nevertheless, the number of users, their visits and the total number of websites views are open for anyone to use, so that's still a lot of useful data. In 
addition to that, Trafic.ro offers the possibility of searching or organizing Romanian websites according to their domain/specific niche, thus allowing anyone interested to see the competitors of the website they are searching for and even have a better understanding of the market in question.

Next, we looked for the companies behind the websites. There are many Romanian online platforms that can be used for obtaining financial data (www.termene.ro, www.datefirme.ro, www.risco.ro, www.firmeo.ro etc.), some of them offering even advanced financial analyzes, in

the case of paid accounts. In this paper, we used the free data offered by www.listafirme.ro and transformed it into a graph using Excel.

For the third and final part of our study (showcased in Figure 2), we used internet instruments that are easy to access and free for everyone. We used Google Chrome Browser for testing the responsiveness of the websites, Google Reviews for looking at the number and quality of the feedback offered by customers and Facebook/Instagram/YouTube for trying to determine their social media presence. While choosing the seven criteria for evaluating the websites, we tried to use and develop elements from similar studies created by other researchers that approached this topic, one of them being The impact of the problems faced by online customers on ecommerce (Sabou et al., 2017).

This study has application in the business world as we take into consideration the current global situation caused by the Covid-19 pandemic. As the physical contact must be reduced as much as possible (in some cases this being enforced by law rather than being a general recommendation), the need to obtain knowledge about the business world is still there, maybe even more than ever in the case of businesses that are internet-based. A large shift in the way companies promote and sell their products and services took place in the last year, most of them going online in order to avoid huge losses due to the restrictions. So, taking into account everything presented above, it makes sense to develop a basic approach that allows a small business to extract knowledge in an exclusively online manner, even if it can't be applied in all domains and niches.

All the data and information used for this study were collected from the internet, proving that it is possible, to some extent, to refine data and information from free online sources in order to create knowledge.

\section{References}

Bratianu, C., Nestian, A.S, Tita, S.M., Voda, A.I. and Guta, A.L. (2020). The Impact of Knowledge Risk on Sustainability of Firms. Amfiteatru Economic, 22(55), 639-652.

Bratianu, C., Prelipcean, G., Bejinaru, R. (2020). Exploring the latent variables which support SMEs to become learning organizations. Management \& Marketing. Challenges for the Knowledge Society, 15(2).

Dima, A. M., Țuclea, C. E., Vrânceanu, D. M., Țigu, G. (2019). Sustainable Social and Individual Implications of Telework: A New Insight into the Romanian Labour Market. Sustainability. 11(13), 3506.

Dinca, V. M. (2020). Factors with impact on the knowledge management practices within shared service centers. Proceedings of the International Conference on Business Excellence, 14(1).

Ferreira, T., Pedrosa I., Bernardino, J. (2017). Business Intelligence for E-commerce: Survey and Research Directions. WorldCIST 2017. Advances in Intelligent Systems and Computing, Vol. 569. Springer, Cham. 
Gavurova, B., Cepel, M., Belas, J., Dvorsky, J. (2020). Strategic Management in SMEs and its Significance for Enhancing the Competitiveness in the V4 Countries - A Comparative Analysis. Management \& Marketing. Challenges for the Knowledge Society, 15(4).

Glavas, C., Mathews, S., and Russell-Bennett, R. (2019). Knowledge acquisition via internetenabled platforms: Examining incrementally and non-incrementally internationalizing SMEs, International Marketing Review, 36(1), 74-107.

Ivan, A. G., Jorge, G., Stefan, S. (2018). Advertising non-premium products as if they were premium: The impact of advertising up on advertising elasticity and brand equity. International Journal of Research in Marketing, 35(3), 471-489.

Lista firmelor din Romania (2020, December 23). Lista Firme. https://www.listafirme.ro.

Mahdavi, M., Barbosa, B., Oliveira, Z., Chkoniya, V. (2019). Scents of celebrities: Endorsers' impact on buyers' online perfume purchase. Management \& Marketing. Challenges for the Knowledge Society, 14(3).

Paunescu, C., Matyus, E. (2020). Resilience measures to dealing with the Covid-19 pandemic. Evidence from Romanian micro and small enterprises, Management \& Marketing. Challenges for the Knowledge Society, 15(S1).

Sabou, S., Avram-Pop, B., Zima, L.A. (2017). The impact of the problems faced by online customers on ecommerce. Studia Universitatis Babes-Bolyai Oeconomica, 62(2).

Stefani, A. (2018). A metrics ecosystem for designing quality e-commerce systems. International Journal of Computer Science \& Information Technology (IJCSIT), 10(2).

Top Siteuri Auto (2020, December 22). Trafic. http://www.trafic.ro/vizitatori/top-siteuri-automoto.

Woodruff, J. (2020, December 29). What is Premium Pricing Strategy?. Chron. https://small business.chron.com/premium-pricing-strategy-1107.html. 